\title{
Differential distribution of tumor-associated macrophages and Treg/Th17 cells in the progression of malignant and benign epithelial ovarian tumors
}

\author{
QINYI ZHU, XIAOLI WU and XIPENG WANG \\ Department of Gynecology, Shanghai First Maternity and Infant Hospital, Tongji University School of Medicine, \\ Shanghai 201204, P.R. China
}

Received August 10, 2015; Accepted November 10, 2016

DOI: $10.3892 / 01.2016 .5428$

\begin{abstract}
Epithelial ovarian cancer (EOC) is one of the predominant causes of cancer-associated mortality in women with gynecological oncology. Tumor-associated macrophages (TAMs), regulatory T cells (Treg cells) and T helper cell 17 (Th17) cells have been hypothesized to be involved in the progression of EOC. However, the association between TAMs and $\mathrm{T}$ cells remains to be elucidated. The aim of the present study was to investigate the differential distribution of TAMs, Treg cells and Th17 cells in benign ovarian tumor tissues and in tissues from patients with EOC, and to examine their association with the clinical pathology of EOC. A total of 126 tissue samples from patients with EOC and 26 tissue samples from patients with benign ovarian tumors were analyzed, and it was identified that the distribution of TAMs, Treg cells, Th17 cells and the ratio of Treg/Th17 cells were higher in the patients with EOC using triple color immunofluorescence confocal microscopy. The high frequency of TAMs and ratio of Treg/Th17 cells in late tumor grades suggested that they may be significant in tumor progression. The frequency of TAMs was different between the histological types of EOC. Immunohistochemistry was used to investigate the microvessel density (MVD) in the EOC and benign ovarian tumor tissues. A higher MVD was observed in the EOC patient tissues, particularly, in the late tumor grade tissues. The present study provided clinical data demonstrating the high distribution of TAMs and T-cells in EOC, which may contribute to tumor progression through angiogenesis. The mechanisms by which TAMs are associated with Treg cells and Th17 cells requires further investigation as prognostic factors and therapeutic targets for EOC.
\end{abstract}

Correspondence to: Dr Xipeng Wang, Department of Gynecology, Shanghai First Maternity and Infant Hospital, Tongji University School of Medicine, 2699 West Gaoke Road, Pudong New Area, Shanghai 201204, P.R. China

E-mail: dr_xwang@hotmail.com

Key words: epithelial ovarian cancer, tumor-associated macrophages, regulatory $\mathrm{T}$ cell, $\mathrm{T}$ helper cell 17, microvessel density

\section{Introduction}

Ovarian cancer is the fourth leading cause of cancer-associated mortality in women in western countries (1). The incidence of epithelial ovarian cancer (EOC)-associated mortality in the United States is estimated to be 15,280 cases per year, with 22,430 newly diagnosed cases of EOC (1). Surgical removal and chemotherapy are the mainstays of treatment for ovarian cancer. However, despite initial responses, the majority of patients eventually develop relapsed disease (2). The pathogenesis of ovarian cancer is a complex process, which involves interactions among inflammatory cells, the environment and hereditary factors. It is also clear that the body's immune system is important in protecting the host from ovarian cancer (3-7). The interaction between ovarian cancer and the immune system is complex, including mechanisms of immune suppression and immune activation (8).

Cancer-associated inflammation is associated with several aspects of malignancy, including the survival and proliferation of malignant cells, tumor angiogenesis and metastasis (9). In the tumor microenvironment, the most abundant immune cell population is that of the tumor-associated macrophages (TAMs) (10). TAMs are derived from monocytes circulating in the blood, and can be recruited to the ovarian tumor site by certain molecules, including transforming growth factor- $\beta$, vascular endothelial growth factor (VEGF) and C-C motif chemokine ligand 5,(11). TAMs affect certain aspects of tumor biology and resemble M2-polaized macrophages in the tumor microenvironment. TAMs are known to have an immunosuppressive role in ovarian cancer, which is associated with poor outcomes (4).

TAMs comprise a large group of the immune cells in the ovarian cancer microenvironment and are capable of regulating $\mathrm{T}$ cell differentiation $(12,13)$. However, the mechanisms affecting TAMs and regulatory $\mathrm{T}$ cells (Treg cells) remain to be elucidated in ovarian cancer. Treg cells are characterized by a $\mathrm{CD} 4^{+} \mathrm{CD} 25^{+}$forkhead box P3 $\left(\mathrm{Foxp}^{+}\right)$phenotype (14). $\mathrm{T}$ helper cell 17 (Th17 cell) is a CD4 ${ }^{+} \mathrm{T}$ helper lymphocyte, which secretes interleukin (IL)-17 (15). Treg cells and Th17 cells share a relevant differentiation pathway from $\mathrm{CD}^{+}$ precursors. The balance between Treg cells and Th17 cells is important to the maintenance of immune homeostasis (16). 
Increased numbers of Treg cells have been reported in several tumors, including those of colorectal cancer, gastric cancer, pancreatic cancer, lung cancer and ovarian cancer $(7,17,18)$. Furthermore, it has been reported that depleting Treg cells can result in antitumor immunity and reduce tumor growth (19). Thus, Treg cells and Th17 cells may interact to shape the immune environment in ovarian cancer.

The aim of the present study was to evaluate the distribution of TAMs, Treg cells and Th17 cells, the ratio of Treg/Th17 cells and the microvessel density (MVD) in tissues from patients with benign ovarian tumors and EOC, and to determine their association with the clinical pathology of EOC.

\section{Materials and methods}

Patients and tissue specimens. The present study included tissue specimens from 126 patients with EOC (mean age, 51.40 years) and tissue specimens from 26 patients with benign ovarian tumors (mean age, 52.15 years). Formalin-fixed and frozen sections of tissue specimens of all cases were obtained from Shanghai First Maternity and Infant Hospital, Tongji University (Shanghai, China). The tissue samples were obtained during surgical resection from January 2009 to December 2014. The major clinical and pathological characteristics of the 152 patients are listed in Table I. Only tissue samples of the central areas of EOC were used, and metastases were excluded. The present study was approved by the Institutional Review Board of the First Maternity and Infant Hospital Affiliated to Tongji University. Written informed consent was obtained from all patients.

Immunofluorescence confocal microscopy. The tissue samples were obtained during surgical resection, approved by the Shanghai First Maternity and Infant Hospital. The frequency of TAMs was evaluated using the F4/80 marker. The frequency of Treg cells was evaluated using CD4 and Foxp3 markers, and the frequency of Th17 cells was evaluated using CD4 and IL-17 markers. The frequencies of TAMs, Treg cells, Th17 cells were calculated, and the ratio of Treg/Th17 was determined in five randomly selected high power fields per tumor tissue (original magnification, $\mathrm{x} 400$ ). The tissue samples were embedded in O.C.T, and $10 \mu \mathrm{m}$ sections were prepared. The slides were fixed with $4 \%$ paraformaldehyde and treated with $0.2 \%$ Triton X-100 (Shenggong Biotech, Shanghai, China) for $5 \mathrm{~min}$ at room temperature. The slides were blocked with $10 \%$ goat serum (Amresco, LLC, Solon, $\mathrm{OH}, \mathrm{USA}$ ) and then incubated with the following antibodies: Rat anti-human F4/80 (1:50; Abcam, Cambridge, MA, USA), mouse anti-human CD4 (1:200; EMD Millipore, Billerica, MA, USA), rat anti-human Foxp3 (1:100; Abcam) and rabbit anti-human IL-17A (1:500; Abcam), followed by incubation with Cy3-conjugated goat anti-rat IgG for F4/80 and Foxp3 detection (1:250; Jackson ImmunoResearch Laboratories, Inc., West Grove, PA, USA), Alexa Flour 488-conjugated goat anti-mouse $\operatorname{IgG}$ for the detection of CD4 (1:250; Jackson, ImmunoResearch Laboratories, Inc), and Alexa Flour 647-conjugated goat anti-rabbit IgG for the detection of IL-17A (1:250; Jackson ImmunoResearch Laboratories, Inc.). For the primary antibodies, the tissues were incubated in PBS overnight at $4^{\circ} \mathrm{C}$. For the secondary antibodies,
Table I. Clinical and pathological characteristics of the 152 patients.

\begin{tabular}{lrr}
\hline Characteristic & $\mathrm{N}$ & $\%$ \\
\hline Diagnosis & & \\
Benign tumor & 26 & 17.11 \\
Invasive carcinoma & 126 & 82.89 \\
Tumor grade & & \\
I & 12 & 9.52 \\
II & 37 & 29.37 \\
III & 77 & 61.11 \\
Clinical stage & & \\
I & 34 & 26.98 \\
II & 30 & 23.81 \\
III & 61 & 48.41 \\
IV & 1 & 0.79 \\
Histological type & & \\
Serous & 81 & 64.29 \\
Mucinous & 14 & 11.11 \\
Endometrioid & 11 & 8.73 \\
Clear cell & 20 & 15.87 \\
\hline
\end{tabular}

the tissues were incubated in PBS for $60 \mathrm{~min}$ at $37^{\circ} \mathrm{C}$. The cell nuclei were stained with DAPI (Sigma-Aldrich; Merck Millipore, Darmstadt, Germany) for $10 \mathrm{~min}$ at $37^{\circ} \mathrm{C}$. Images were captured with a ZEISS LSM 510 scanning confocal microscope (Zeiss AG, Oberkochen, Germany).

Analysis of MVD via immunohistochemical staining for CD31. For immunohistochemical analysis of the tumor samples from patients with benign ovarian tumors and EOC, samples were collected and embedded in O.C.T for frozen section analysis. Sections of $10 \mu \mathrm{m}$ were prepared, and stained with hematoxylin and eosin. The detection of MVD was performed using mouse anti-human monoclonal CD31 (1:100; Abcam). The tumors tissues were fixed with $4 \%$ paraformaldehyde. Sections of $10 \mu \mathrm{m}$ were prepared, and the slides were fixed in cold acetone for $20 \mathrm{~min}$. Following PBS washes, endogenous peroxide was blocked with $3 \%$ $\mathrm{H}_{2} \mathrm{O}_{2}$ for $10 \mathrm{~min}$ at room temperature. The slides were blocked with $10 \%$ normal goat serum for $90 \mathrm{~min}$ at room temperature, followed by incubation with mouse anti-human monoclonal CD31 (1:100; Abcam) in PBS overnight at $4^{\circ} \mathrm{C}$. Biotin-SP-conjugated affinipure goat anti-mouse IgG (1:600; Jackson ImmunoResearch Laboratories, Inc.) was added for $30 \mathrm{~min}$ at $37^{\circ} \mathrm{C}$, and horseradish peroxidase (1:800; Jackson ImmunoResearch Laboratories) was added for $45 \mathrm{~min}$ at $37^{\circ} \mathrm{C}$. Subsequently, the samples were detected using 3,3'-diaminobenzidine (Sigma-Aldrich; Merck Millipore) as a substrate for $3 \mathrm{~min}$, followed by counterstaining with hematoxylin (Sigma-Aldrich; Merck Millipore). The MVD was calculated in five randomly selected high power fields per tumor tissue (original magnification, x200). Vessels with a linear vessel shape or well-defined lumen were considered to be a blood microvessel. A negative control was also included 
A

B
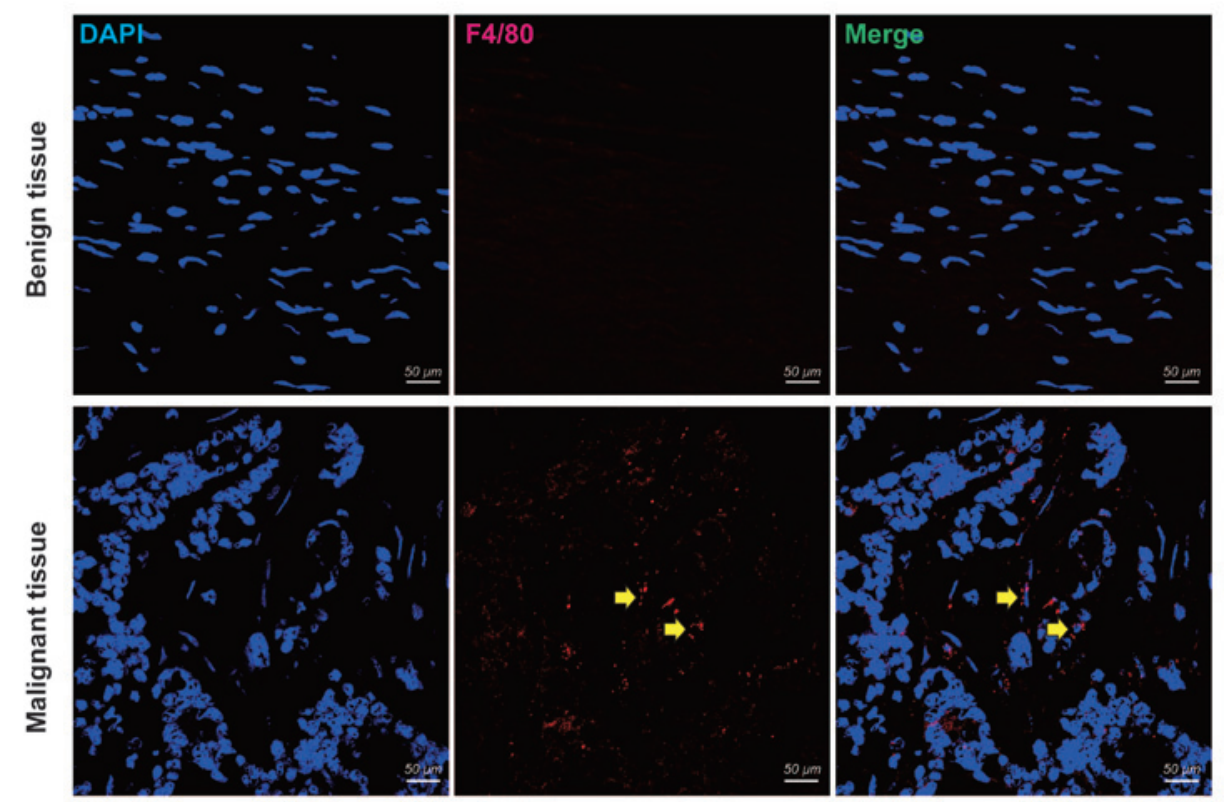

C

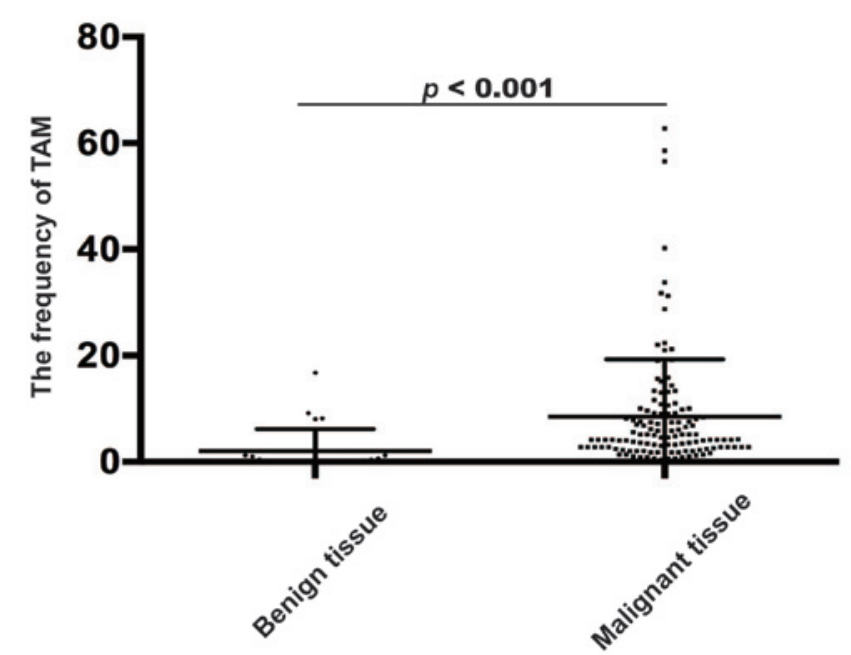

Figure 1. Expression of tumor-associated macrophages using immunofluorescence staining. (A) TAMs were stained by DAPI (Blue; nuclei) and F4/80 (Red) in benign tumor tissues. (B) TAMs were stained by DAPI (Blue; nuclei) and F4/80 (Red) in EOC tissues. The yellow arrows indicate TAMs. (C) Frequency of TAMs was significantly higher in EOC tissues, compared with benign tumor tissues. Scale bar=50 $\mu$ m. EOC, epithelial ovarian cancer; TAM, tumor-associated macrophage.

by replacing CD31 with PBS. The same conditions were used as those used for the mouse anti-human monoclonal CD31 antibody.

Statistical analysis. Statistical analysis was performed using SPSS software (version 22.0; IBM SPSS, Armonk, NY, USA). The data obtained from the patients with EOC were compared with data from the patients with benign ovarian tumors. $\mathrm{P}<0.05$ was considered to indicate a statistically significant difference using the Mann-Whitney nonparametric test. The frequency of TAMs, ratio of Treg/Th17 cells and MVD in the EOC tissues of different tumor grades and histological types were also calculated using the Mann-Whitney U test. Data are expressed as the mean \pm standard deviation. Graphs were prepared using GraphPad Prism 6 (GraphPad, Software Inc., La Jolla, CA, USA) and continuous variables in figures are expressed as the mean \pm standard error of the mean.

\section{Results}

Frequency of TAMs is high in patients with EOC. To confirm the frequency of TAMs, tissue samples from 126 patients with malignant EOC and 26 patients with benign tumors were analyzed using triple color immunofluorescence confocal microscopy (Fig. 1A and B). Compared with the benign tumor tissues $(2.05 \pm 4.12)$, the frequency of TAMs, which were defined as $\mathrm{F} 4 / 80^{+}$cells, was significantly higher in the EOC tissues $(8.48 \pm 10.81)$, as determined using a Mann-Whitney $U$ test $(\mathrm{P}<0.001$; Fig. $1 \mathrm{C})$. This result showed that TAMs may be significant in the progression of EOC.

Frequencies of Treg cells and Th17 cells, and the ratio of Treg/Th17 cells are high in patients with EOC. Tissue samples from the 126 patients with malignant EOC and 26 patients with benign tumors were also used to confirm the frequencies 
A

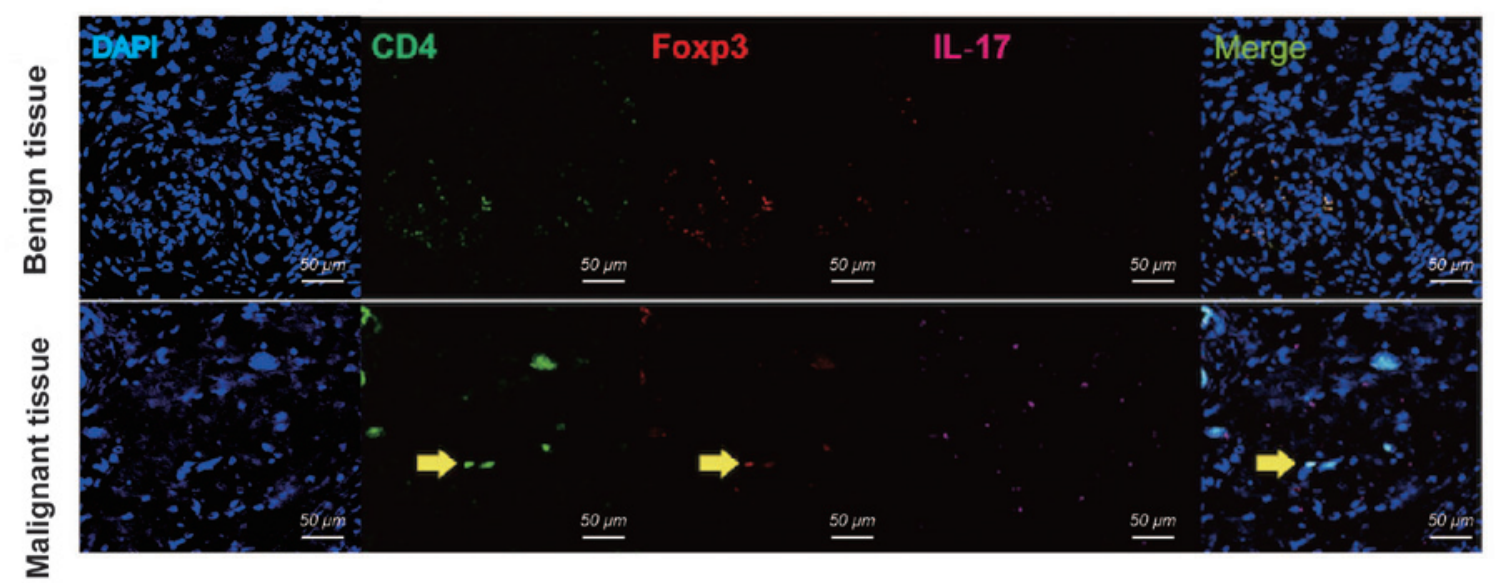

C
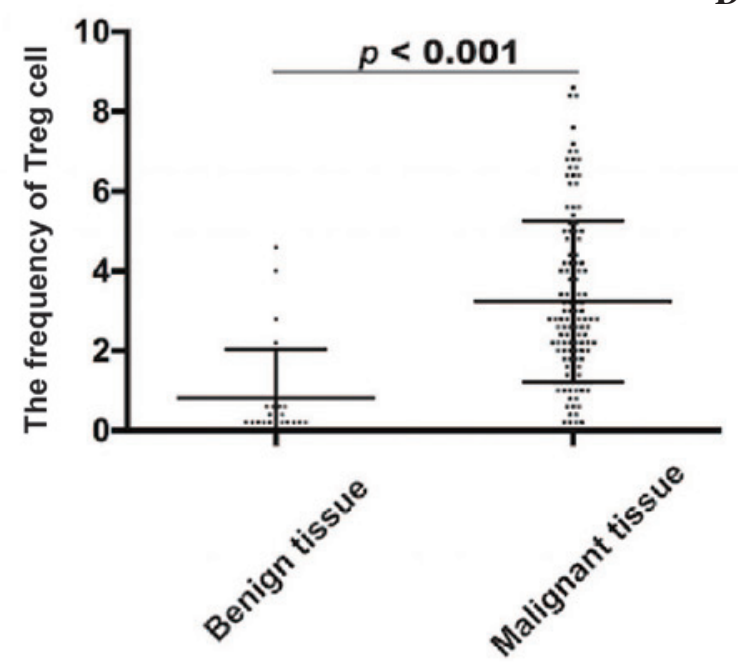

$\mathbf{E}$

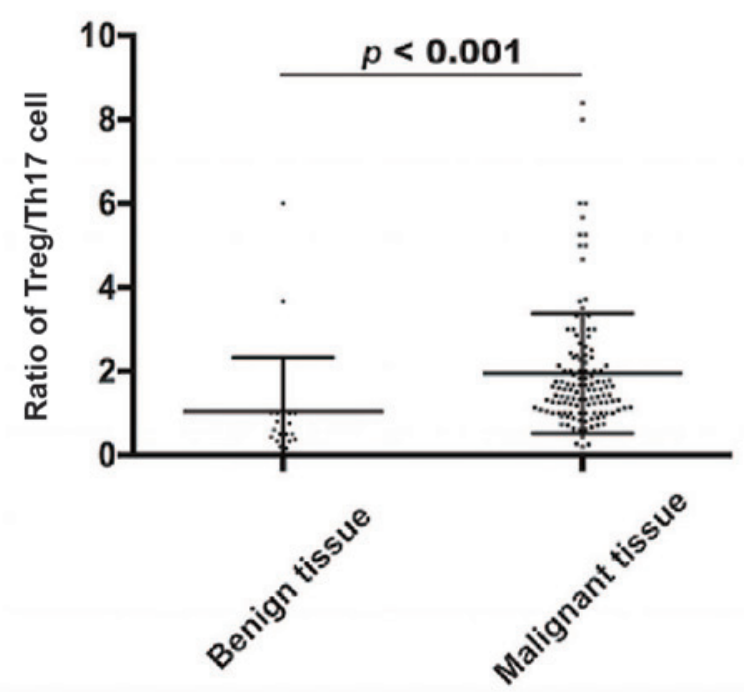

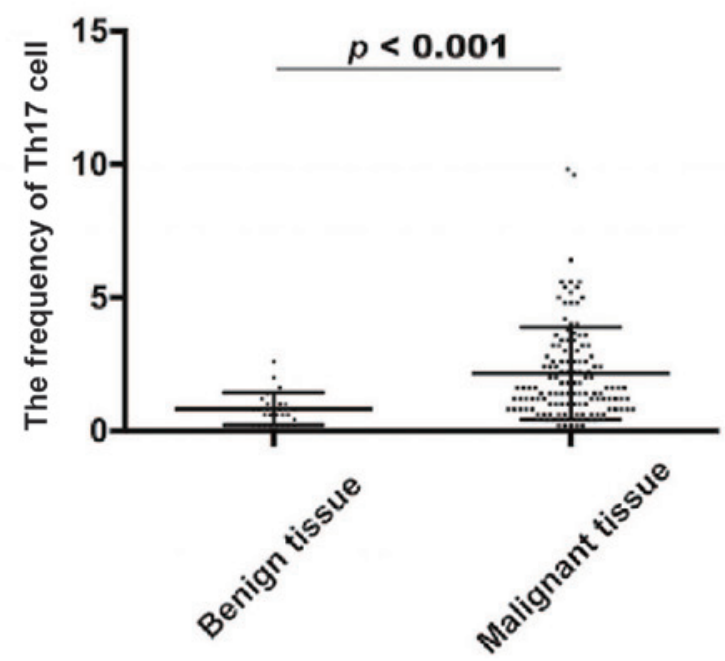

Figure 2. Expression of Treg cells and Th17 cells using immunofluorescence staining. (A) Treg cells or Th17 cells were stained by DAPI (Blue), CD4 (Green) and Foxp3 (Red; IL-17 for Th17 cells) in benign tumor tissues. (B) Treg cells or Th17 cells were stained by DAPI (Blue), CD4 (Green) and Foxp3 (Red; IL-17 for Th17 cells) in EOC tissues. The yellow arrows indicate TAMs. The frequency of (C) Treg cells, frequency of (D) Th17 cells and (E) ratio of Treg/Th17 cells were significantly higher in EOC tissues, compared with the benign tumor tissues. Scale bar=50 $\mu \mathrm{m}$. EOC, epithelial ovarian cancer; TAM, tumor-associated macrophage; Treg, regulatory T cell; Th17, T helper cell 17; IL-17: interleukin 17.

of Treg cells and Th17 cells. The frequency of Treg cells was evaluated using CD4 and Foxp3 markers (Fig. 2A and B), and the frequency of Th17 cells was evaluated using CD4 and IL-17 markers (Fig. 2A and B). Compared with the benign tumor tissues $(0.82 \pm 1.21)$, the frequency of Treg cells was significantly higher in the EOC tissues $(3.23 \pm 2.02)$, as determined 
A

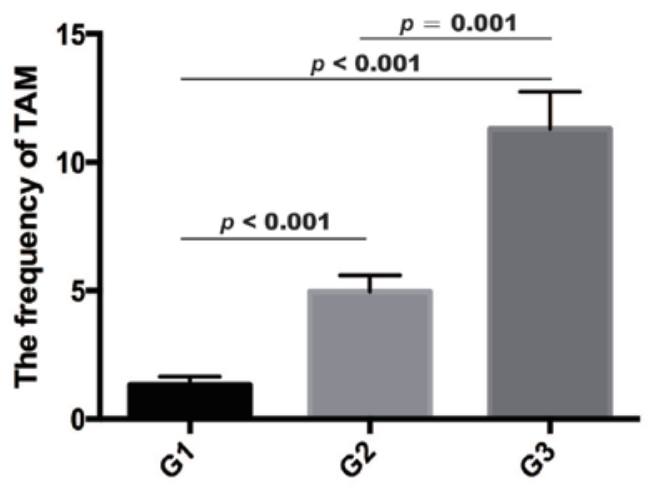

B

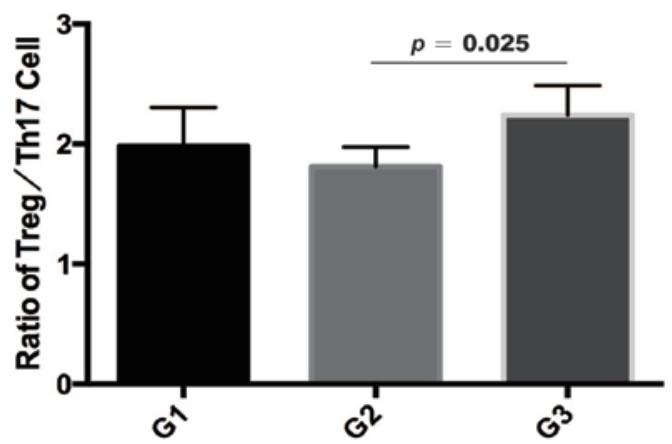

Figure 3. Distribution of TAMs and ratio of Treg/Th17 cells in EOC tumors of different grades. (A) Frequency of TAMs in different EOC tumor grades. (B) Ratio of Treg/Th17 cells in different EOC tumor grades. EOC, epithelial ovarian cancer; TAM, tumor-associated macrophage; Treg, regulatory $\mathrm{T}$ cell; Th17, T helper cell 17.

using a Mann-Whitney $\mathrm{U}$ test $(\mathrm{P}<0.001$; Fig. 2C). In addition, the frequency of Th17 cells was significantly higher in the EOC tissues $(2.15 \pm 1.74)$, compared with the benign tumor tissues (0.82 \pm 0.61 ; Mann-Whitney U test; $\mathrm{P}<0.001$; Fig. 2D). Similarly, the ratio of Treg/Th17 cells was higher in the EOC tissues (1.95 \pm 1.43$)$, compared with the benign tumor tissues (1.04 \pm 1.29 ; Mann-Whitney U Test; $\mathrm{P}<0.001$; Fig. 2E). Therefore, the results showed that the distribution of Treg cells and Th17 cells, and the ratio of Treg/Th17 cells were increased in the EOC microenvironment, compared with benign tumor microenvironment.

Distribution of TAMs and ratio of Treg/Th17 cells differ between EOC tumor grades. As mentioned above, the frequencies of TAMs, Treg cells and Th17 cells, and the ratio of Treg/Th17 cells in benign tumor tissues and EOC tissues were evaluated using immunofluorescence. The frequency of TAMs was significantly higher in tissues of grade III $(11.29 \pm 12.75 ; n=77)$ tumors, compared with those of grade II $(4.95 \pm 3.92 ; n=37)$ and grade I $(1.33 \pm 1.06$; $\mathrm{n}=12$ ) tumors, determined using a Mann-Whitney $U$ test $(\mathrm{P}<0.001$ for grades I and II; $\mathrm{P}<0.001$ for grades I and III; $\mathrm{P}=0.001$ for grades II and III; Fig. 3A). Furthermore, the ratio of Treg/Th17 cells was also higher in grade III tumor tissues $(1.81 \pm 1.43)$, compared with that in grade II tumor tissues $(2.24 \pm 1.51)$, determined using the Mann-Whitney U test $(\mathrm{P}=0.025$; Fig. 3B). However, no significant difference
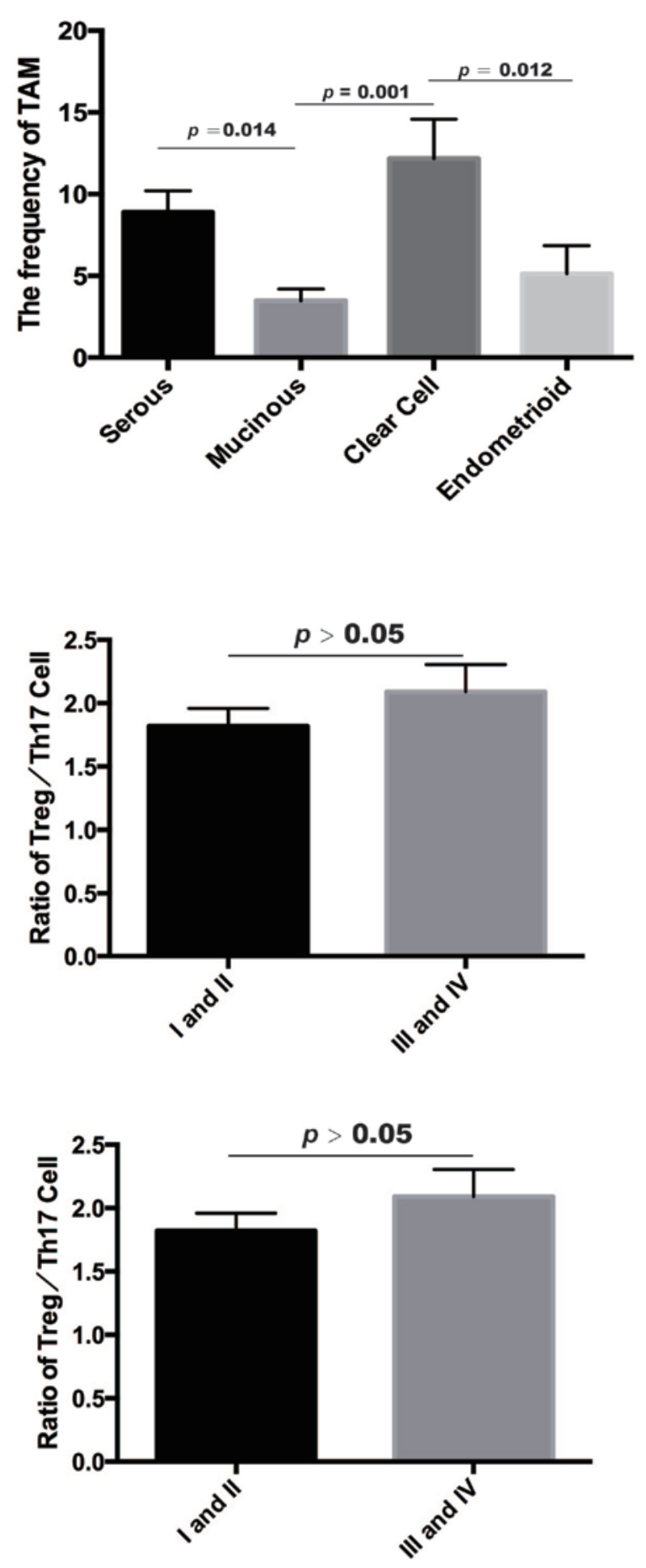

Figure 4. Distribution of TAMs in different histological types of EOC. The frequency of TAMs was distributed differently between histological types of EOC. EOC, epithelial ovarian cancer; TAM, tumor-associated macrophage.

was found in the ratio of Treg/Th17 cells between grade I $(1.98 \pm 1.11)$ and grade II EOC tissues $(\mathrm{P}>0.05)$. These results suggested that their expression correlated with ovarian carcinoma formation.

Frequency of TAMs between histological types of EOC. In the EOC tissues, the frequency of TAMs was higher in 
A

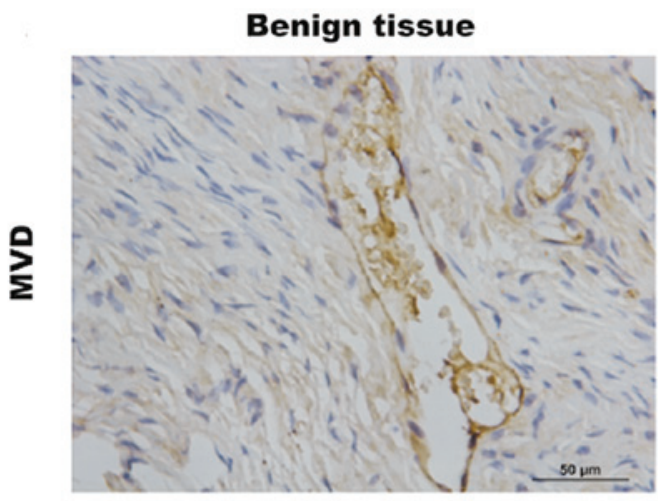

B

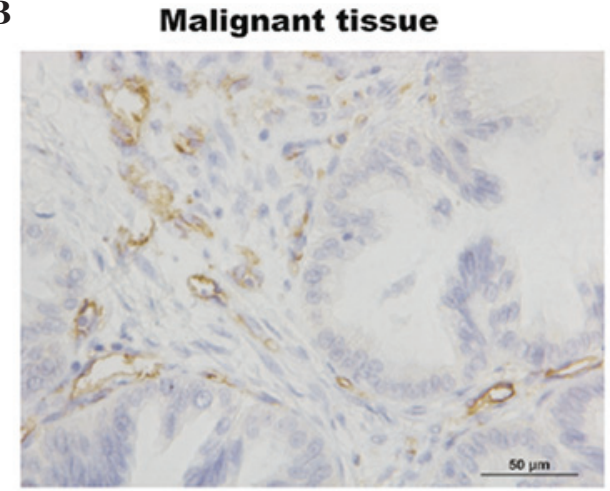

C

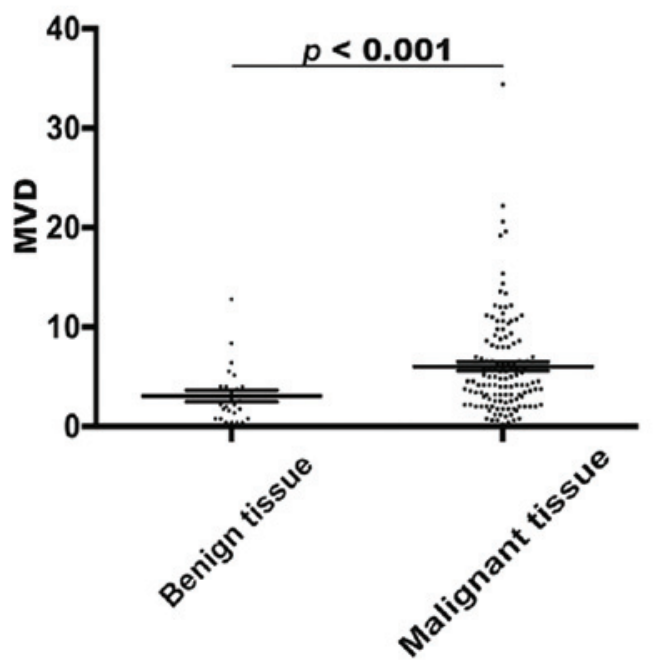

D

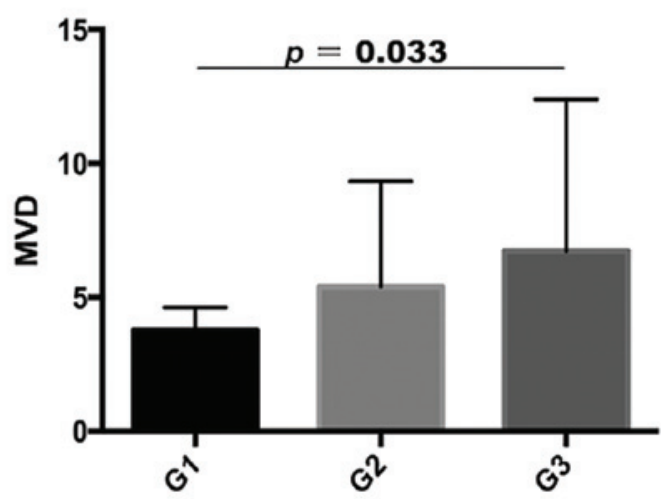

Figure 5. Expression of MVD in benign tumor and EOC tissues. (A) MVDs were identified using immunohistochemistry in benign tumor tissues and (B) EOC tissues. Scale bar=50 $\mu \mathrm{m}$. (C) MVD was significantly higher in EOC tissues, compared with benign tumor tissues. (D) MVD was higher in grade III tumor tissue, compared with in grade I tumor tissues. EOC, epithelial ovarian cancer; MVD, microvascular density; G, tumor grade.

clear cell ovarian cancer $(12.17 \pm 10.75 ; \mathrm{n}=20)$, compared with that in endometrimoid ovarian cancer $(5.13 \pm 5.68 ; n=11$; Mann-Whitney $\mathrm{U}$ test, $\mathrm{P}=0.012$ ). The frequency of TAMs was also higher in clear cell ovarian cancer, compared with mucinous ovarian cancer $(3.47 \pm 2.73$; $n=14$; Mann-Whitney U test, $\mathrm{P}=0.001)$. The frequency of TAMs was higher in serous ovarian cancer $(8.89 \pm 11.85 ; n=81$; Mann-Whitney $U$ test, $\mathrm{P}=0.014)$ compared with that in mucinous ovarian cancer (Fig. 4). However, no significant differences in the frequency of Treg cells, Th17 cells or ratio of Treg/Th17 were found among these subtypes. In addition, no significant differences ( $P>0.05)$ were found in the frequency of TAMs or ratio of Treg/Th17 cells between early stages [International Federation of Gynecology and Obstetrics (FIGO)] I and II] and late stages (FIGO III and IV) (20). These results demonstrated that TAMs may have a substantial effect on the grade of EOC.

MVD in benign tumor and EOC tissues. To investigate the angiogenesis in benign tumor tissues and EOC tissues, the MVDs were evaluated using immunohistochemistry (Fig. 5A and B). The MVD in the EOC patient tissues (6.06 +5.06$)$ was significantly higher, compared with that in the benign tumor patient tissues (3.08 \pm 2.85 ; Mann-Whitney $\mathrm{U}$ test, $\mathrm{P}<0.001$; Fig. 5C). In addition, the MVDs were higher in grade III $(6.74 \pm 5.65 ; n=77)$ tumors, compared with grade I $(3.77 \pm 2.94$, $\mathrm{n}=12$ ) tumors (Mann-Whitney U test, $\mathrm{P}=0.033$; Fig. 5D). However, no significant difference in MVDs were found between grade II $(5.39 \pm 3.93 ; n=37)$ and grade III EOC patient tissues $(\mathrm{P}>0.05)$. Thus, it was hypothesized that TAMs may promote the progression of ovarian tumor through angiogenesis.

\section{Discussion}

Ovarian cancer is one of the leading causes of cancer-associated mortality in women with gynecological oncology. Although surgery and chemotherapy are the mainstays of treatment for ovarian cancer, the five-year-survival rate of patients with ovarian cancer is $\sim 40 \%$ (21). Therefore, novel targets require improvement for the treatment of ovarian cancer. The tumor microenvironment in ovarian cancer may be a potential therapeutic target and contains several types of immune cell, which result in tumor progression. TAMs are the most abundant type of immune cell in the tumor microenvironment. A study by Colvin (2014) reported that TAMs can create an immunosuppressive microenvironment and lead to tumor cells evading immune detection (22). However, which cells TAMs interact with and the mechanism by which TAMs promote ovarian cancer remain to be elucidated 
Treg cells, which were evaluated using the $\mathrm{CD} 4^{+} \mathrm{Foxp} 3^{+}$ marker in the present study, are a specific population of T cells, which mediate homeostatic peripheral tolerance $(23,24)$ and function as suppressors of autoimmune reactions $(25,26)$. Treg cells can infiltrate into ovarian cancer cells and suppress the tumor specific $\mathrm{T}$ cell immune response, which may result in tumor growth. There is evidence that TAMs and Treg cells mediate the invasiveness of several types of cancer, including endometrial cancer, breast cancer, prostate cancer and colorectal cancer $(18,27,28)$. In addition, studies have reported that TAMs and T cells may be important in the progression of EOC (28-30). The present study provided a clinical data that high frequencies of TAMs, Treg cells, Th17 cells and ratio of Treg/Th17 were infiltrated into EOC tissues, compared with benign tumor tissues. These results indicated potential associations among TAMs, Treg cells, Th17 cells and the ratio of Treg/Th17 cells with the progression of EOC. Consistent with these findings, previous studies have reported similar results, reporting an increased number of TAMs in ovarian cancer, compared with benign tumors $(12,31,32)$, and others have reported that Treg cells can be a predictive factor for prolonged survival rates, with a marked reduction in the mortality rates of patients with ovarian carcinoma (30).

TAMs and Treg cells have synergistic effects in promoting ovarian cancer proliferation, tumor angiogenesis and metastasis $(33,34)$. Therefore, TAMs and Treg cells may be potential targets for the immunotherapy of EOC. On consideration of the association between TAMs and Treg cells, the present study hypothesized that TAMs may be correlated with Treg cells or the ratio of Treg/Th17 cells in EOC. However, no significant correlation was found among TAMs, Treg cells, Th17 cells or the ratio of Treg/Th17 cells in EOC. Therefore, further examination of the mechanism underlying their function in EOC is required, which was a limitation of the present study. Furthermore, the frequency of TAMs and the ratio of Treg/Th17 cells in grade III tumor tissues were higher, compared with those in low grade EOC tissues. In accordance, a previous study reported that Treg cells exhibited increased expression in high grade EOC, compared with low grade EOC (35).

Previous studies have also reported a correlation between TAMs and MVD in malignant human tumors (36-39). Therefore, the present study investigated the trend towards a higher MVD in EOC tissues, compared with benign tumor tissues. Similar to the result described above revealing the high expression of TAMs in the EOC tissues, it was demonstrated and that TAMs contributed to oncogenesis and neoplasm growth through tumor angiogenesis. Previous studies have also reported that Treg and Th17 cells may lead to tumor angiogenesis, by Th17 cells secreting IL-17 and Treg cells affecting the expression of VEGF $(40,41)$. Thus, the present study also analyzed the association between the ratio of Treg/Th17 and MVD. No significant association was found between the ratio of Treg/Th17 and MVD. This result may be due to differences in sample size between the EOC and benign ovarian tumors, and requires further investigation.

Taken together, the present study showed that the immune system was involved in the progression of ovarian cancer. Higher frequencies of TAMs, Treg cells, Th17 cells, ratio of Treg/Th17 cells and MVDs in malignant tissues may be significant in tumor growth. Further experiments on TAMs, Treg cells and Th17 cells are required in the future for revealing their potential as immune therapeutic targets in ovarian carcinoma.

\section{Acknowledgements}

This study was supported by grants from the National Science Foundation of China (grant nos. 81372787 and 81072136), and the Top 100 Medical Elite in Shanghai (grade no. XBR 2011065).

\section{References}

1. Siegel R, Naishadham D and Jemal A: Cancer statistics, 2012. CA Cancer J Clin 62: 10-29, 2012.

2. Yap TA, Carden CP and Kaye SB: Beyond chemotherapy: Targeted therapies in ovarian cancer. Nat Rev Cancer 9: 167-181, 2009.

3. Dunn GP, Old LJ and Schreiber RD: The immunobiology of cancer immunosurveillance and immunoediting. Immunity 21 : 137-148, 2004.

4. Shah CA, Allison KH, Garcia RL, Gray HJ, Goff BA and Swisher EM: Intratumoral T cells, tumor-associated macrophages, and regulatory T cells: Association with p53 mutations, circulating tumor DNA and survival in women with ovarian cancer. Gynecol Oncol 109: 215-219, 2008.

5. Milne K, Köbel M, Kalloger SE, Barnes RO, Gao D, Gilks CB, Watson PH and Nelson BH: Systematic analysis of immune infiltrates in high-grade serous ovarian cancer reveals CD20, FoxP3 and TIA-1 as positive prognostic factors. PloS One 4: e6412, 2009.

6. Adams SF, Levine DA, Cadungog MG, Hammond R, Facciabene A, Olvera N, Rubin SC, Boyd J, Gimotty PA and Coukos G: Intraepithelial T cells and tumor proliferation: Impact on the benefit from surgical cytoreduction in advanced serous ovarian cancer. Cancer 115: 2891-2902, 2009.

7. Kryczek I, Wei S, Zhu G, Myers L, Mottram P, Cheng P, Chen L, Coukos G and Zou W: Relationship between B7-H4, regulatory $\mathrm{T}$ cells, and patient outcome in human ovarian carcinoma. Cancer Res 67: 8900-8905, 2007.

8. Matsuzaki J, Gnjatic S, Mhawech-Fauceglia P, Beck A, Miller A, Tsuji T, Eppolito C, Qian F, Lele S, Shrikant P, et al: Tumor-infiltrating NY-ESO-1-specific $\mathrm{CD} 8^{+} \mathrm{T}$ cells are negatively regulated by LAG-3 and PD-1 in human ovarian cancer. Proc Natl Acad Sci USA 107: 7875-7880, 2010.

9. Witz IP: The tumor microenvironment: The making of a paradigm. Cancer Microenviron 2 Suppl 1: 9-17, 2009.

10. Allavena P, Sica A, Solinas G, Porta C and Mantovani A: The inflammatory micro-environment in tumor progression: The role of tumor-associated macrophages. Crit Rev Oncol Hematol 66: $1-9,2008$.

11. Yaal-Hahoshen N, Shina S, Leider-Trejo L, Barnea I, Shabtai EL, Azenshtein E, Greenberg I, Keydar I and Ben-Baruch A: The chemokine CCL5 as a potential prognostic factor predicting disease progression in stage II breast cancer patients. Clin Cancer Res 12: 4474-4480, 2006.

12. Wang X, Deavers M, Patenia R, Bassett RL Jr, Mueller P, Ma Q, Wang E and Freedman RS: Monocyte/macrophage and T-cell infiltrates in peritoneum of patients with ovarian cancer or benign pelvic disease. J Transl Med 4: 30, 2006.

13. Mantovani A and Allavena P: The interaction of anticancer therapies with tumor-associated macrophages. J Exp Med 212: 435-445, 2015.

14. Fontenot JD, Gavin MA and Rudensky AY: Foxp3 programs the development and function of $\mathrm{CD} 4{ }^{+} \mathrm{CD} 25^{+}$regulatory $\mathrm{T}$ cells. Nat Immunol 4: 330-336, 2003.

15. Ouyang W, Kolls JK and Zheng Y: The biological functions of T helper 17 cell effector cytokines in inflammation. Immunity 28 : 454-467, 2008.

16. Chen Z, Ding J, Pang N, Du R, Meng W, Zhu Y, Zhang Y, Ma C and Ding Y: The Th17/Treg balance and the expression of related cytokines in Uygur cervical cancer patients. Diagn Pathol 8: 61, 2013.

17. Charbonneau B, Moysich KB, Kalli KR, Oberg AL, Vierkant RA, Fogarty ZC, Block MS, Maurer MJ, Goergen KM, Fridley BL, et al: Large-scale evaluation of common variation in regulatory $\mathrm{T}$ cell-related genes and ovarian cancer outcome. Cancer Immunol Res 2: 332-340, 2014. 
18. Liu J, Zhang N, Li Q, Zhang W, Ke F, Leng Q, Wang H, Chen J and Wang H: Tumor-associated macrophages recruit CCR6 ${ }^{+}$ regulatory $\mathrm{T}$ cells and promote the development of colorectal cancer via enhancing CCL20 production in mice. PloS One 6: e19495, 2011.

19. Zou W: Regulatory T cells, tumour immunity and immunotherapy. Nat Rev Immunol 6: 295-307, 2006.

20. Xiaodan Meng, Volkmar Müller, Karin Milde-Langosch, Fabian Trillsch, Klaus Pantel and Heidi Schwarzenbach: Circulating cell-free mir-373, mir-200a, mir-200b and mir-200c in patients with epithelial ovarian cancer. Adv Exp Med Biol 924: 3-8, 2016

21. Winter WE III, Maxwell GL, Tian C, Carlson JW, Ozols RF, Rose PG, Markman M, Armstrong DK, Muggia F and McGuire WP; Gynecologic Oncology Group Study: Prognostic factors for stage III epithelial ovarian cancer: A Gynecologic Oncology Group Study. J Clin Oncol 25: 3621-3627, 2007.

22. Colvin EK: Tumor-associated macrophages contribute to tumor progression in ovarian cancer. Front Oncol 4: 137, 2014.

23. Salvi S, Segalla F, Rao S, Arienti F, Sartori M, Bratina G, Caronni E, Anichini A, Clemente C, Parmiani G, et al: Overexpression of the T-cell receptor beta-chain variable region TCRBV14 in HLA-A2-matched primary human melanomas. Cancer Res 55: 3374-3379, 1995.

24. Curiel TJ, Coukos G, Zou L, Alvarez X, Cheng P, Mottram P, Evdemon-Hogan M, Conejo-Garcia JR, Zhang L, Burow M, et al.: Specific recruitment of regulatory $\mathrm{T}$ cells in ovarian carcinoma fosters immune privilege and predicts reduced survival. Nat Med 10: 942-949, 2004.

25. Barnett B, Kryczek I, Cheng P, Zou W and Curiel TJ: Regulatory $\mathrm{T}$ cells in ovarian cancer: Biology and therapeutic potential. Am J Reprod Immunol 54: 369-377, 2005.

26. Dietl J, Engel JB and Wischhusen J: The role of regulatory $\mathrm{T}$ cells in ovarian cancer. Int J Gynecol Cancer 17: 764-770, 2007.

27. Eljaszewicz A, Wiese M, Helmin-Basa A, Jankowski M, Gackowska L, Kubiszewska I, Kaszewski W, Michalkiewicz J and Zegarski W: Collaborating with the enemy: Function of macrophages in the development of neoplastic disease. Mediators Inflamm 2013: 831387, 2013

28. Sasaki A, Tanaka F, Mimori K, Inoue H, Kai S, Shibata K, Ohta M, Kitano S and Mori M: Prognostic value of tumor-infiltrating $\mathrm{FOXP}^{+}$regulatory $\mathrm{T}$ cells in patients with hepatocellular carcinoma. Eur J Surg Oncol 34: 173-179, 2008.

29. Mhawech-Fauceglia P, Wang D, Ali L, Lele S, Huba MA, Liu S and Odunsi K: Intraepithelial $\mathrm{T}$ cells and tumor-associated macrophages in ovarian cancer patients. Cancer Immun 13: 1, 2013.
30. Sato E, Olson SH, Ahn J, Bundy B, Nishikawa H, Qian F, Jungbluth AA, Frosina D, Gnjatic S, Ambrosone C, et al: Intraepithelial $\mathrm{CD}^{+}$tumor-infiltrating lymphocytes and a high $\mathrm{CD}^{+}$/regulatory $\mathrm{T}$ cell ratio are associated with favorable prognosis in ovarian cancer. Proc Natl Acad Sci USA 102: 18538-18543, 2005.

31. Klimp AH, Hollema H, Kempinga C, van der Zee AG, de Vries EG and Daemen T: Expression of cyclooxygenase-2 and inducible nitric oxide synthase in human ovarian tumors and tumor-associated macrophages. Cancer Res 61: 7305-7309, 2001.

32. Kawamura K, Komohara Y, Takaishi K, Katabuchi H and Takeya M: Detection of M2 macrophages and colony-stimulating factor 1 expression in serous and mucinous ovarian epithelial tumors. Pathol Int 59: 300-305, 2009.

33. Pittet MJ: Behavior of immune players in the tumor microenvironment. Curr Opin Oncol 21: 53-59, 2009

34. Zamarron BF and Chen W: Dual roles of immune cells and their factors in cancer development and progression. Int J Biol Sci 7: 651-658, 2011.

35. Leffers N, Gooden MJ, de Jong RA, Hoogeboom BN, ten Hoor KA, Hollema H, Boezen HM, van der Zee AG, Daemen T and Nijman HW: Prognostic significance of tumor-infiltrating T-lymphocytes in primary and metastatic lesions of advanced stage ovarian cancer. Cancer Immunol Immunother 58: 449-459, 2009.

36. Tjiu JW, Chen JS, Shun CT, Lin SJ, Liao YH, Chu CY, Tsai TF, Chiu HC, Dai YS, Inoue H, et al: Tumor-associated macrophage-induced invasion and angiogenesis of human basal cell carcinoma cells by cyclooxygenase-2 induction. J Invest Dermatol 129: 1016-1025, 2009.

37. Shieh YS, Hung YJ, Hsieh CB, Chen JS, Chou KC and Liu SY: Tumor-associated macrophage correlated with angiogenesis and progression of mucoepidermoid carcinoma of salivary glands. Ann Surg Oncol 16: 751-760, 2009.

38. Toge H, Inagaki T, Kojimoto Y, Shinka T and Hara I: Angiogenesis in renal cell carcinoma: The role of tumor-associated macrophages. Int J Urol 16: 801-807, 2009.

39. Soeda S, Nakamura N, Ozeki T, Nishiyama H, Hojo H, Yamada H, Abe M and Sato A: Tumor-associated macrophages correlate with vascular space invasion and myometrial invasion in endometrial carcinoma. Gynecol Oncol 109: 122-128, 2008.

40. Gnerlich JL, Mitchem JB, Weir JS, Sankpal NV, Kashiwagi H, Belt BA, Porembka MR, Herndon JM, Eberlein TJ, Goedegebuure P and Linehan DC: Induction of Th17 cells in the tumor microenvironment improves survival in a murine model of pancreatic cancer. J Immunol 185: 4063-4071, 2010.

41. Hou F, Li Z, Ma D, Zhang W, Zhang Y, Zhang T, Kong B and Cui B: Distribution of Th17 cells and Foxp3-expressing T cells in tumor-infiltrating lymphocytes in patients with uterine cervical cancer. Clin Chim Acta 413: 1848-1854, 2012. 